\title{
MEDIADORES DE CENTROS DE CIÊNCIAS E OS SEUS PAPÉIS DURANTE AS VISITAS ESCOLARES
}

\author{
Camila Silveira da Silva* \\ Luiz Antonio Andrade de Oliveira**
}

RESUMO: Neste artigo apresenta-se um panorama sobre quem são e o que fazem os mediadores de centros e museus de Ciência A literatura aponta os diversos papéis que possuem esses sujeitos e também que a presença desses profissionais nas instituições de educação não-formal já é algo consolidado. Também são apresentados e discutidos dados obtidos junto a mediadores de um centro de Ciências focando o papel desses sujeitos durante as visitas escolares mediadas, com o objetivo de caracterizar as ações que cabem a esses profissionais. Os dados construídos e analisados apontaram que, durante as visitas escolares, os papéis que cabem aos mediadores são: (a) mediar o conhecimento; (b) explicar os conceitos científicos envolvidos nas exposições; (c) apresentar os espaços temáticos; (d) receber e organizar os visitantes; (e) zelar pelo espaço físico e integridade física e moral dos visitantes; (f) complementar e ensino escolar dos visitantes e $(\mathrm{g})$ difundir conhecimento científico.

Palavras-chave: Mediadores; Centros e Museus de Ciências; Visitas Escolares Mediadas.

\section{SCIENCE CENTERS MEDIATORS AND THEIR ROLES DURING SCHOOL VISITS}

ABSTRACT: In the present paper, it is presented a general view about who they are and the activities science centers and museums mediators develop. The literature points out to the diverse roles attributed to these actors and that the presence of this type of professional is a consolidated practice in non-formal educational institutions. Data obtained among the mediators of a science center during mediated school visits are also presented and discussed, focusing in the role attributed to these professionals, with the objective of characterizing their actions during these visits. The data obtained and analyzed showed that during school visits, the roles that are attributed to the mediators are: (a) mediation of the knowledge involved in the expositions; (b) explanation of the scientific concepts involved in the expositions; (c) presentation of the thematic spaces; (d) reception and organization of groups of visitors; (e) preservation of the physical and moral integrity of the visitors, and the integrity of the physical spaces and their equipments; (f) complementation of the school knowledge, and $(\mathrm{g})$ diffusion of the scientific knowledge.

Keywords: Mediators; Centers and Museums of Sciences; Mediated School Visits.

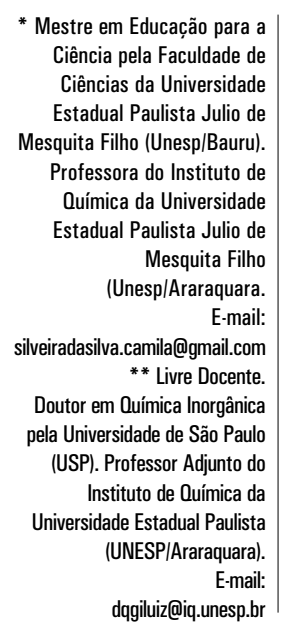




\section{OS MEDIADORES NOS CENTROS E MUSEUS DE CIÊNCIAS}

Os profissionais que atuam no atendimento ao público das visitas monitoradas ${ }^{1}$ são chamados de monitores, de mediadores, ajudantes, facilitadores, instrutores, guias, explicadores (Massarani, 2007), dependendo dos papéis que desempenham de acordo com o objetivo de cada museu ou centro de Ciências em que atuam. Neste texto chamaremos, na maioria das vezes, esses profissionais de monitores, pois é como são identificados os sujeitos da investigação que será abordada, na instituição em que trabalham. Mas, considerando que o papel central desses monitores é a mediação, por alguns momentos nos referiremos a eles como mediadores também.

Sendo os centros e museus de Ciências, espaços de educação não-formal e de comunicação, "podem ser considerados contextos privilegiados para a construção de diálogos compartilhados entre grupos, em função de estímulos oferecidos por uma exposição temática" (BONATTO et al, 2007, p. 48). Nesse caso, a interatividade é oportunizada por meio da mediação, sendo a linguagem, falada ou escrita, fundamental nesse processo.

Uma das formas de comunicação é a mediação e esta pode ser discutida sob vários aspectos, como do ponto de vista social, cultural, pedagógico e em termos de relação de sociabilidade, como aponta Azevedo (2008). Segundo essa autora, do ponto de vista social, a "mediação pode se constituir como um elemento essencial dos processos sociais". Do ponto de vista cultural, "a mediação reflete a diversidade cultural e cria várias interações, proporcionando a inclusão cultural e gerando novas formas culturais". Em termos de relações de sociabilidade, "a mediação permite a construção criativa de novas formas de relacionamento com o outro contribuindo, deste modo, para o desenvolvimento afetivo e social e promovendo práticas potenciadoras de bem-estar pessoal e relacional". Do ponto de vista pedagógico, "a mediação é fundamental para o desenvolvimento cognitivo, das auto-aprendizagens e das competências" (AZEVEDO, 2008, p. 20).

Davallon (2003) $)^{2}$ analisou o uso do termo "mediação" utilizado em diversos trabalhos com o intuito de incitar uma nova forma de pensar a comunicação. Ele centra sua discussão referindo-se à mediação cultural, definindo-a em nível funcional, em que sua ação consiste em construir uma interface entre o público e o objeto cultural com a finalidade de "permitir uma apropriação do segundo pelo primeiro". A mediação cultural se aplica à prática profissional dos mediadores; uma forma de ação cultural por oposição à animação cultural; a construção de uma relação com a arte; produtos destinados a apresentar ou a explicar a arte ao público; etc (DAVALLON, 2003, p. 4).

No caso dos museus, esses "atuam como dispositivos de mediação, pois têm desenvolvido práticas de interação entre os diversos agentes culturais e sociais" (AZEVEDO, 2008, p. 20).

Segundo Falcão (2007), citado por Bonatto et al, 2007, p. 49, "'a mediação de exposições trata de um potencial conflito entre a intenção dos idealizado- 
res da exposição e a interpretação dos visitantes". A mediação pode ser realizada de diversas formas e a partir de diversos recursos. Ela pode ser realizada por pessoas, a mediação humana; por textos explicativos; imagens; som; vídeos; modelos; experimentos; jogos; painéis; recursos multimídia, a mediação instrumental (Moraes et al, 2007, p. 58).

Referindo-se à mediação em centros e museus de Ciências vinculada à aprendizagem numa perspectiva socioconstrutivista, Moraes et al (2007) descrevem que mediar é: (a) promover diálogos que possibilitem aos visitantes avançarem naquilo que já conhecem, sempre com a ajuda de quem conhece mais; (b) a ação do outro que ajuda a aprender, a dar um passo a diante naquilo que já se conhece; (c) desafiar o outro a se envolver na reconstrução do que já conhece, produzindo mais conhecimento; (d) auxiliar o outro a apropriar-se de forma mais intensa de discursos em que já está envolvido; (e) assumir um novo entendimento de aprender; (f) provocar o conhecimento de alguém para criar condições de produzir novos saberes; $(\mathbf{g})$ provocar diálogos entre visitantes e experimentos; $(\mathbf{h})$ transformar os experimentos da exposição em desafios, perguntas a serem respondidas pelos visitantes; (i) provocar conflitos cognitivos nos visitantes; (j) ajudar a perceber outros sentidos, compartilhando entendimentos e ampliando significados que os visitantes conseguem elaborar por conta própria em relação aos objetos expostos; (k) ampliar as interpretações e complexificar os significados que podem ser produzidos; (I) acompanhar a vivência do outro, o visitante, andando com ele e provocando-o para que tire maior proveito em seu mergulho no discurso da Ciência presente no museu e $(\mathrm{m})$ mostrar a diversidade de oportunidades de aprender num ambiente como os museus e centros de Ciências (MORAES et al, 2007, p. 56-58).

$\mathrm{Na}$ perspectiva da mediação humana como forma de comunicação entre público e exposição, torna-se essencialmente importante a presença do mediador. Segundo Azevedo (2008), o mediador

é um terceiro elemento num processo de construção de uma qualquer realidade fortemente comunicacional no qual desempenha o papel simultaneamente de tradutor, facilitador, negociador, anfitrião, embaixador, parceiro, moderador, descodificador, orientador, catalisador e intermediário entre dois ou mais interlocutores, tendo como cenário diferentes contextos de sociabilidade, sendo por isso a sua identidade redefinida constantemente. (AZEVEDO, 2008, p. 11)

Alguns autores já indicaram que o papel e a formação dos mediadores são temas que necessitam de aprofundamentos, como Grusman e Siqueira (2007) que, ao discorrerem sobre o papel educacional dos museus de Ciências, apontam que o papel dos mediadores é um assunto que ainda merece maior atenção.

Dentro da organização institucional dos centros e museus de Ciências, destina-se ao atendimento ao público uma equipe de estagiários, geralmente 
estudantes universitários, que auxilia nos experimentos, dá informações e esclarece dúvidas sobre as exposições (FAHL, 2003, p. 79). De maneira geral, os monitores pertencem a diversas instituições de Ensino Superior e possuem jornada semanal que varia entre 10 e 20 horas semanais, com casos em que o monitor pode atuar até 40 horas na semana (PAVÃO; LEITÃO, 2007, p. 43). Mas, também existem instituições nas quais alunos de Ensino Médio ou pessoas da comunidade atuam como monitores (GOUVEIA et al, 2007). A distribuição do número de monitores pelas atividades nos centros e museus de Ciências, a jornada de cada um, os dias da semana em que atuam variam de acordo com cada instituição.

Pavão e Leitão (2007) descrevem que, no caso dos centros e museus de Ciências, "não há como duvidar do poder da linguagem do mediador", reconhecendo que o papel do monitor possui um potencial extremamente significativo para mediar processos de construção do conhecimento, pois por intermédio de sua "intervenção competente, os visitantes são estimulados a interagirem uns com os outros e com o objeto do conhecimento. Ao estimular essas trocas, o monitor favorece a criação de um espaço de comunicação e interlocução de saberes.” (PAVÃO; LEITÃO, 2007, p. 41). Os monitores do museu de Ciência em que eles trabalham são alunos tanto do Ensino Médio quanto do Ensino Superior e desempenham funções como desenvolvimento de pesquisas, apresentação de propostas inovadoras, produção de material para oficinas, além da atividade de atendimento ao público (p. 43).

Segundo Ribeiro e Frucchi (2007), os mediadores "não são personagens adestrados para cumprir um ritual e/ou repetir explicações. São educadores-comunicadores cuja atuação interdisciplinar tornou-se essencial no cumprimento das ações educativas e de divulgação de conhecimento nos museus" (RIBEIRO; FRUCCHI, 2007, p. 70).

Sendo os monitores das exposições científicas de espaços como centros e museus de Ciências os mediadores entre o que propõe a exposição e o público que a visita, atribui-se a esse profissional um importante valor para que os objetivos das exposições sejam atingidos. Os monitores "ocupam papel central dado que são eles que, considerando-se as visitas escolares, concretizam a comunicação da instituição com o público e propiciam o diálogo com os visitantes acerca das questões presentes no museu, ressignificando-as junto a esses" (STANDERSKI, 2007, p. 2-3). Assim, a forma com que essa mediação humana é realizada deve ser investigada de modo mais aprofundado, pois

não é qualquer mediação que garante uma compreensão efetiva e uma experiência prazerosa em uma visita ao museu. Aqueles que costumam visitar exposições certamente já vivenciaram experiências positivas e negativas de mediação, ambas fornecendo material para reflexão sobre essa ação. Além disso, é cada vez maior a consciência de que o mediador é, de certa forma, a "voz" da instituição, o elemento de ligação entre o museu e o público. (MARANDINO, 2008, p. 12) 
Na perspectiva de autores como Bennet e Thompson (1990); Almeida e Lopes (2003); Cuesta et al (2003); todos citados por Ribeiro (2005), a presença de um monitor numa exposição "poderá ser um poderoso instrumento para focalizar a atenção do visitante e iniciar um primeiro passo no processo de aprendizagem provocando discussões, incitando a observação e orientando grupos" (RIBEIRO, 2005, p. 48).

Segundo Ribeiro (2005), a maior parte dos museus e centros de Ciências já possui indivíduos especializados nas áreas das Ciências Naturais que têm como função levar a cabo determinadas demonstrações na sua área de especialização, ou desenvolver atividades com os visitantes ${ }^{3}$. Ainda sobre esses indivíduos, ela diz que esses possuem a função de estimular e ajudar os visitantes, fazendo uso de "vestuário com cores muito garridas para poderem ser localizados em qualquer momento" (RIBEIRO, 2005, p. 48).

Teoricamente, os monitores devem transmitir de forma homogênea, para todos visitantes, a mesma mensagem geral sobre as exposições, o que torna o seu trabalho bastante complexo já que os visitantes possuem conhecimentos e níveis de interesse diferentes (Sápiras, 2007, p. 13, citando Munley, 1987).

Queiroz et al (2002) afirmam que "o mediador pode colaborar para tornar uma visita significativa, preenchendo o vazio que muitas vezes existe entre o que foi idealizado e a interpretação dada pelo público ao que está exposto" e consideram que "a mediação requer um saber com dimensões peculiares: o saber da mediação” (QUEIRÓZ et al 2002).

Rodari e Merzagora (2007) citam que uma das habilidades mais importantes que um mediador deve ter é a capacidade de ouvir:

Para as pessoas que administram os museus, os mediadores podem funcionar como um ouvido gigante à disposição para escutar a voz do público. Todos os dias, em todo o mundo, eles ouvem milhões de visitantes. Eles sabem, ou têm o potencial para saber, quais são as questões-chave, as maiores esperanças e as mais fortes preocupações a respeito do desenvolvimento científico e tecnológico. (RODARI; MERZAGORA, 2007, p. 10)

Os mesmos autores apontam ainda que, em toda a Europa, a maior parte dos mediadores exerce a atividade como um trabalho temporário. A maior parte deles são estudantes na área de disciplinas científicas, recebem baixos salários (são pagos por hora) e a rotatividade desses indivíduos é alta (p. 14).

No artigo que explora a capacitação dos mediadores do Techniquest, Johnson (2007), ao final do texto, define qual é o papel dos mediadores:

Os mediadores são as principais "portas de entrada e saída" dos museus e centros de Ciência. Seu papel é dar as boas-vindas aos visitantes, não cuidar de objetos. Eles precisam ser considerados e treinados como guias particulares e não como funcionários da instituição. Eles estão presentes em uma exposição para animar o ambiente e não para oferecer os objetos aos visitantes do tipo "pegar ou largar". Esperamos que eles ensinem, mas pela experiência e prática e não pela instrução didática. É obrigação deles, na medida do possível, explicar a Ciência para aqueles que querem saber mais, 
mas, mais especificamente, eles devem desenvolver a capacidade de fazer a pergunta certa para aprofundar e enriquecer a experiência do visitante. Finalmente, eles tem um papel crucial para se obter um feedback de como o público avalia os módulos expostos e sobre o comportamento dos visitantes, ajudando o centro a gerar respostas de forma adequada. (JOHNSON, 2007, p. 37-38)

Para um mediador cumprir bem o seu papel, Matssura (2007) descreve o que é necessário:

o mediador deve conhecer não só os conteúdos científicos, mas também os aspectos humanos e sociais da Ciência e os reflexos da Ciência e tecnologia no cotidiano. Deve ainda ter a capacidade de se expressar com correção, clareza, concisão e elegância, ter o dom de intuir ou inferir os conhecimentos prévios do público, saber dosar os conteúdos, ser capaz de estimular a curiosidade e de conduzir um diálogo reflexivo, ter carisma, senso de humor e espírito lúdico. Em outras palavras: o bom mediador é aquele que não age burocraticamente, que evita atitudes professorais e se coloca no nível do público para poder dialogar com ele e, de forma interativa, construir o conhecimento. (MATSUURA, 2007, p. 78)

Para Gaspar (1993), em relação à apresentação das exposições, cabe aos monitores: (a) nortear as observações dos visitantes; (b) dar as explicações corretas e adequadas ao público que dela participa e (c) responder às perguntas que esse público faz. O autor apoia-se na teoria de Vigotski ${ }^{4}$, ao enunciar que

um monitor deve ser, sempre que possível, o parceiro mais capaz nas interações sociais que ocorrem espontaneamente, ou por ele provocadas junto aos experimentos. Convém evitar a postura tradicional de professor, preocupado com a apresentação de um conteúdo previamente definido, transformando sua fala em uma monótona aula expositiva, a menos que seja a de um professor que priorize o diálogo e, com ele, a interação social. Nesse sentido, o monitor deve preocupar-se com o nível cognitivo do visitante, tentar detectar a definição de situação que cada um cria em relação às demonstrações apresentadas; procurar não ser óbvio no que diz, restringindo-se a interação à zona de desenvolvimento do passado, de seus interlocutores, nem muito rigoroso ou pretensioso, ultrapassando os limites da zona de desenvolvimento imediato desses interlocutores. Não há regras infalíveis que assegurem ou garantam a eficiência de uma interação social, entretanto, algumas orientações básicas devem favorecêlas: falar menos e ouvir mais; perguntar menos e responder mais; preocupar-se menos com o rigor dos conceitos emitidos e mais com a capacidade de compreensão desses conceitos, por parte dos visitantes, manifestada por seus interlocutores (e se eles não a manifestam, procurar fazer com que o façam). (GASPAR, 2006, p. 183-184)

As possibilidades de ação dos mediadores são inúmeras e variam de acordo com a instituição em que atuam. Há espaços de educação não-formal nos quais, além da atividade de mediar visitas, outras ações são executadas por esses indivíduos, como por exemplo: atividades de desenvolvimento de exposições permanentes, temporárias e itinerantes; kits de empréstimos; produção de material impresso/jogos; planejamento e realização de oficinas, palestras, animações em vídeo, circo, teatro, contação de histórias, trilhas educativas e sites. 
Stuchi e Ferreira (2003) realizaram uma pesquisa junto a uma exposição da Estação Ciência ${ }^{5}$ e destacaram a importância dos monitores em exposições científicas fazendo uso de observações sobre diversas situações que envolviam esses sujeitos, como no caso em que se referem à leitura das etiquetas (encontradas em cada equipamento e com informações a respeito desses) pelos visitantes. Eles notaram que algumas pessoas observavam os equipamentos por muito tempo e recorriam às etiquetas para obter explicações a respeito e muitas vezes essas pessoas não compreendiam o significado nelas contido, cabendo ao monitor, nesses casos, dar explicações mais detalhadas e de linguagem simples. Os referidos autores destacaram que a presença do monitor nesse tipo de caso é bastante fundamental, pois "quando os monitores não estão presentes, mesmo as pessoas mais atentas às etiquetas, não demoram mais que um minuto frente aos experimentos" (STUCHI; FERREIRA, 2003). Também sobre a ocorrência de interações sociais ${ }^{6}$, eles apontaram que essas ocorrem quando os monitores dialogam sobre determinado experimento com o público visitante o que pode vir a favorecer a aprendizagem de conceitos científicos e incorporam a esse conceito a definição de situação e mediação semiótica, ou seja, à forma com que o monitor explora os objetos da exposição sobre determinado conteúdo temático para o entendimento pelo visitante, sendo a linguagem o veículo que leva o conhecimento às pessoas e que se estrutura sobre os recursos que o monitor utiliza em uma explicação. Assim, ao atingirem os objetivos propostos em sua pesquisa, intervindo em uma exposição temática específica, os autores concluíram que a linguagem dos visitantes nas respostas dos testes e entrevistas que realizaram, foi veiculada pelo monitor, sem o qual não se completaria o processo ensino-aprendizagem dos experimentos. Pode-se verificar isso, comparando o nível das respostas dos testes dadas antes e depois da exposição. A influência do discurso do monitor nas respostas dadas depois da visita foi significativa (STUCHI \& FERREIRA, 2003). Desse modo, a linguagem utilizada pelos monitores está diretamente associada à compreensão da exposição, bem como a forma com que interagem com o público, o que requer um preparo e formação contínua desses profissionais.

Sobre o papel desempenhado pelos monitores na apresentação das exposições, Fahl (2003, p. 86) notou diferenças na atuação dos monitores em relação às visitas escolares e não-escolares. Em suas observações, notou que na visita escolar, o monitor: (i) fala mais, conduz o diálogo geralmente de duas maneiras diferenciadas: na maioria das vezes se estabelece uma dinâmica que possibilita a explanação do monitor acompanhada dos questionamentos e observações dos visitantes escolares. Porém, ocorreram também situações em que o monitor conduziu o "diálogo", apresentando uma síntese dos conhecimentos científicos; (ii) estimula a participação do grupo de alunos; (iii) inicia a interação com o experimento ou atividade, utilizando-se da explanação e (iv) controla o tempo do grupo em um determinado espaço, tentando atender rapidamente as expectativas do grupo. Em relação à visita não-escolar, notou que o monitor: 
(i) geralmente coloca-se como observador; (ii) não inicia a explanação, a não ser quando é solicitado pelo visitante; (iii) fala menos, utiliza-se de poucas palavras, aguardando a fala do visitante; (iv) permite ao visitante transitar livremente entre os experimentos; (v) não controla o tempo que o visitante fica em um determinado espaço e (vi) não conduz o diálogo. Estabelece a comunicação com o visitante e procura uma dinâmica que propicie a sua participação.

Da interação do monitor com o visitante escolar (aluno, professor ou acompanhante), Fahl (2003, p. 96) notou que, na visitação escolar: (i) necessariamente a presença do monitor se faz sentir, pois no momento da recepção alguns monitores são apresentados aos alunos e professores e conduzem breves diálogos que variam conforme a postura individual do monitor. Porém, todos salientam a necessidade de que os alunos andem em grupo e sigam as orientações de cada monitor; (ii) nem todos os monitores recebem os alunos, pois a maioria fica em "seus postos", nas plataformas, aguardando a chegada do grupo de alunos e (iii) a recepção feita na plataforma não segue um padrão determinado, como em casos observados em que o monitor, talvez pressionado pelo tempo disponível para o atendimento, explanou um rápido cumprimento e iniciou sua fala sobre a plataforma ou sobre um objeto determinado na exposição. Essas observações sobre a interação do monitor com os visitantes também apontaram que, dependendo de como o monitor atua, os grupos de visitantes apresentam comportamentos diferenciados.

Ribeiro (2005), em sua investigação sobre a aprendizagem em centros e museus de Ciências, dedicou atenção ao papel e desempenho dos monitores, discutindo esse tema nas perspectivas dos professores que acompanham as visitas escolares e dos alunos visitantes. Ela solicitou que os professores se posicionassem, mediante uma ficha de observação elaborada pela própria pesquisadora sobre alguns aspectos referentes a atuação dos monitores, tais como conhecimento sobre todos os módulos expostos, estratégias utilizadas para a condução da atividade, entusiasmo e empenho, concretização dos objetivos, utilização de linguagem científica rigorosa, rigor científico na transmissão dos conhecimentos, relação aluno/monitor e outros que o professor julgasse importante e que não fora contemplado pela pesquisadora na ficha de observação proposta. Os professores deviam classificar cada item com uma das opções: nada importante; pouco importante; importante; muito importante ou não responder. A análise permitiu constatar que as "estratégias utilizadas para a condução da atividade experimental" foram um dos aspectos considerados como muito importante por um número bastante significativo de docentes $(39,9 \%)$, bem como a "relação aluno/ monitor" (39,3\%) e o "rigor científico na transmissão dos conhecimentos" (38,3\%). Mais da metade dos inquiridos $(55,2 \%)$ considerou importante "a concretização dos objetivos" (p. 126). No caso dos alunos visitantes, também sujeitos da pesquisa de Ribeiro, estes consideraram a presença dos monitores importante (93\%), argumentando que os mesmos "esclareciam dúvidas", "eram divertidos e simpáticos" e não permitiam que "os colegas se portassem mal” (p. 134). 
Recorrendo às ideias de Almeida e Lopes (2003), Ribeiro (2005) aponta que a ação dos monitores, ao mesmo tempo em que pode facilitar a interação com a exposição, pode também “criar 'ruídos' na comunicação, quando, eventualmente, não obteve a confiança do grupo que orienta e, então, a atividade ficará prejudicada pela falta de concentração e por possíveis animosidades" (RIBEIRO, 2005, p. 48). A autora chama a atenção para a importância que deve ser dada à preparação e formação contínua dos monitores, bem como à constante reavaliação das estratégias utilizadas por eles.

Silva e Gaspar (2007) também destacam que a forma de apresentação feita pelo monitor pode vir a prejudicar o desenvolvimento das atividades e o alcance dos objetivos citando que, em alguns casos, a falta de percepção do monitor das diferentes definições de situação que os visitantes fazem do que está sendo exposto e da própria inadequação da linguagem que utiliza, pode ser atribuído à escolha indevida das atividades ou à sua falta de preparo para adequá-las à provável $\mathrm{ZDI}^{7}$ dos visitantes. E nesse ponto, urge a necessidade desses profissionais pensarem sobre sua prática, sendo orientados por pessoas mais experientes, para que possam ser estimulados a refletir sobre a sua atuação e avaliar se os objetivos propostos no planejamento da atividade são atingidos quando elas são concluídas.

Parece que a competência profissional que cabe aos mediadores de centros e museus de Ciências é oriunda das próprias instituições, produto de suas tradições culturais e das pessoas que compõe esse contexto, legitimando os saberes que são necessários a um monitor em sua prática profissional, cabendo a esse ir apropriando-se dos elementos constituintes de sua prática profissional ao longo de sua formação.

Diante do contexto apresentado, é possível perceber que o monitor/mediador é um indivíduo bastante essencial na equipe de profissionais que compõem o quadro de pessoal dos centros e museus de Ciências e que carrega consigo grandes responsabilidades. O panorama sobre quem são e o que fazem os monitores/mediadores de centros e museus de Ciência aponta que o papel desses sujeitos já é algo consolidado nas instituições de educação não-formal. Assim, neste texto apresentaremos e discutiremos dados obtidos junto a mediadores de um centro de Ciências focando o papel desses sujeitos durante as visitas escolares mediadas, com o objetivo de caracterizar as ações que cabem a esses profissionais, no universo em que atuam. Delimitamos o universo de atuação às visitas escolares, buscando compreender melhor as especificidades dessa dimensão educativa. 


\section{ASPECTOS METODOLÓGICOS}

A pesquisa se caracteriza como uma pesquisa qualitativa do tipo estudo de caso (ANDRÉ, 2005). Os dados apresentados foram obtidos no desenvolvimento de uma pesquisa de mestrado e, junto a outros, compuseram uma dissertação sobre a formação e atuação de monitores de um centro de Ciências. O percurso metodológico pautou-se nas fases que constituem um estudo de caso: (a) exploratória (definição do caso, contatos iniciais, localização dos participantes, estabelecimento de procedimentos de coleta de dados); (b) delimitação do estudo e de coleta de dados (delimitação de focos, entrevistas, questionários, observação de campo, análise de documentos) e (c) análise sistemática dos dados e de elaboração do relatório (organização do material, identificação de pontos relevantes, apresentação dos dados além da descrição).

Por meio de um questionário (GIL, 1991), coletamos dados gerais sobre o perfil dos monitores ${ }^{8}$, mediadores de visitas escolares, de um centro de Ciências vinculado a uma Instituição de Ensino Superior pública, localizado em uma cidade do interior do Estado de São Paulo. Foram convidados a participar da investigação apenas os monitores que possuíam vínculo como bolsistas, pelo motivo de atuarem com frequência no programa de visitação da Instituição. $\mathrm{O}$ questionário foi aplicado a cada monitor individualmente, no mês de julho de 2008, com o objetivo de levantarmos um perfil geral sobre esses sujeitos. Outro questionário foi aplicado após um período de três meses de atuação dos monitores em visitas escolares com o objetivo de que os questionamentos propostos pudessem levar os monitores a pensarem sobre alguns elementos de sua prática e sobre algumas ações que realizavam durante a mediação dos espaços temáticos. Neste artigo, focaremos apenas a questão que abordou o papel dos monitores nas visitas escolares. Tivemos a participação de todos os monitores que atuam em visitas escolares, totalizando 18 participantes.

Ao longo da apresentação dos dados utilizaremos códigos ao nos referirmos aos sujeitos desta pesquisa e, assim, usaremos letras do alfabeto para identificar cada monitor. Eles serão identificados como Monitor A, Monitor B e assim por diante.

Os dados foram analisados tendo como base a Análise de Conteúdo pautada nas ideias de Bardin sobre a análise categorial. Fizemos uma análise temática, buscando identificar os "núcleos de sentido" que compõem a comunicação e que podiam ter significados para o objetivo da pesquisa (BARDIN, 1977; 2000). As categorias foram criadas a posteriori, após leitura de todas as respostas dos monitores. 


\section{O PERFIL DOS MEDIADORES}

A partir do levantamento dos dados, obtivemos que a maior parte dos mediadores (69\%) possui idade entre 18 e 20 anos. Quanto ao gênero, a predominância é do sexo masculino $(75 \%)$.

Os monitores são exclusivamente estudantes universitários de uma instituição pública de Ensino Superior do Estado de São Paulo. A maioria é de alunos do curso de Licenciatura em Química e os demais se dividem entre os cursos de Farmácia-Bioquímica, Letras e Ciências Sociais. Em relação à formação escolar na Educação Básica, a maioria cursou o Ensino Fundamental todo em escola pública $(69 \%)$ e o Ensino Médio todo em escola particular (56\%).

Sobre a formação complementar, a maioria dos mediadores (94\%) já realizou algum curso. Os cursos de Línguas prevaleceram, mas também é importante ressaltar que alguns desses sujeitos também já realizaram cursos de teatro, dança, canto e música; cursos que podem contribuir de maneira bastante significativa na atuação de um monitor, por trabalharem a questão da expressão, da exposição ao público, da criatividade, do uso da voz, dentre outros aspectos.

A maior parte dos monitores demanda um tempo extra para se preparar para as visitas. Aqueles que responderam não gastar nenhum tempo justificaram que se preparam no próprio centro de Ciências.

\section{OS PAPÉIS DOS MEDIADORES NAS VISITAS ESCOLARES}

A questão explorada neste artigo foca o papel do monitor nas visitas escolares mediadas. $\mathrm{Na}$ análise das respostas, procuramos destacar todos os papéis que os monitores atribuíram a si próprios. A quantidade de papéis encontrada foi extensa, mas puderam ser agrupados em grandes categorias como descreveremos a seguir.

\section{Categoria 1 - Mediar o conhecimento.}

Os monitores atribuíram a si o papel de mediar o conhecimento, ressaltando que são intermediários entre o conteúdo científico envolvido nos experimentos ou atividades e o aprendizado do aluno visitante. Os monitores, como mediadores do saber, apontam que seu papel é semelhante ao de um professor.

$\mathrm{Na}$ mediação entre público e exposição, o monitor deve possuir elementos que orientem sua prática profissional. Realizar a mediação de uma exposição de Ciências requer conhecimentos sobre diversos aspectos da Educação e da Comunicação, um aprimoramento constante a partir das mais variadas experiências vividas durante a mediação em uma visita. O mediador precisa conhecer o seu público, saber os conceitos científicos, instigar os visitantes. Mediar exposições científicas, torná-las acessíveis ao público, é uma tarefa complexa e é a função principal do mediador, é o "carro-chefe" desse profissional. 
"O meu papel de monitor nas visitas não deixa de ser diferente do professor, uma vez que também estamos mediando o saber, mesmo não sendo um espaço formal de ensino." (Monitor D)

"O monitor é um mediador do processo experimento-aluno, que passa todo o conhecimento para o aluno adequando a sua linguagem." (Monitor K)

\section{Categoria 2 - Explicar os conceitos científicos envolvidos nas exposições.}

A explicação dos conceitos científicos envolvidos nos equipamentos, modelos, atividades experimentais, objetos expostos, em todas as atividades desenvolvidas pelos monitores durante uma visita guiada é primordial, segundo nossos sujeitos investigados. O modo com que essa explicação deve ser feita por um monitor, durante uma apresentação, também foi descrito por eles.

Adequar a linguagem visando à melhor comunicação e ao entendimento dos diferentes tipos de alunos, expressar-se de forma clara, simples, objetiva, divertida, correta e de acordo com a idade dos visitantes, foram atitudes que os monitores apontaram como essenciais na explicação dos conceitos científicos para os visitantes. Também destacaram que a explicação deve ser feita com dedicação, amor e felicidade, para auxiliar os visitantes no entendimento dos conceitos, além de ser cauteloso na escolha dos materiais a serem apresentados.

Para a maioria dos monitores, uma visita escolar guiada a um centro de Ciências, de nada vale se os alunos não aprenderem ou se os monitores não ensinarem algum conceito científico.

“...cabe, assim, ao monitor, levar o conceito, o conteúdo de uma maneira simples e direta (além de divertida).” (Monitor $\mathrm{H}$ )

"Além disso, tenho que ter a preocupação em transmitir o conteúdo de cada experimento de forma correta e adequada para cada idade." (Monitor I)

\section{Categoria 3 - Apresentar os espaços temáticos.}

A apresentação dos espaços temáticos, focando os objetivos específicos de cada um deles e as atividades que contemplam, é também um papel dos mediadores. Essa apresentação, segundo os mediadores, requer preparo desses profissionais, entusiasmo e dedicação. Pelo fato de um centro de Ciências ser um espaço de aprendizagem e enriquecimento cultural diferente do que os visitantes estão acostumados a ver nas escolas, os monitores destacam que a apresentação de cada ambiente é algo motivador, pois os visitantes, de imediato, demonstram curiosidade, tornando essa função bastante característica de um monitor, que já possui afinidade com o ambiente em questão e, por isso, tem condições de apresentá-lo com bastante propriedade, conduzindo a visita de acordo com orientações recebidas previamente. Sendo o espaço físico da instituição, algo determinante na condução da visita, cabe ao monitor explorá-lo da maneira mais significativa possível, elaborando percursos que permitam conexões entre um espaço temático e outro, que cative os visitantes, 
tomando cuidado também para que a apresentação não canse o público e torne a visita algo desgastante.

"Meu papel é de passar informações sobre as experiências, sobre os aparelhos, os objetos explicando a função de cada instrumento." (Monitor G)

\section{Categoria 4 - Receber e organizar os visitantes.}

Tal categoria também é bastante peculiar dos profissionais que trabalham em centros e museus de Ciências e lidam constantemente com o público. A recepção dos visitantes, segundo os mediadores, é algo muito importante durante as visitas, pois é um fator determinante para que se estabeleça uma relação agradável entre monitores e visitantes. Os visitantes podem se sentir acolhidos e retornar ao centro de Ciências outras vezes se a recepção for bem sucedida. Já na recepção, os visitantes podem ter a sensação do que está por vir, podem avaliar como é a instituição, como ela é organizada, a disciplina, educação e simpatia (ou não!) de seus monitores, enfim, se a primeira impressão é a que fica, os monitores sabem que têm o papel de recepcionar bem os seus visitantes.

A organização dos visitantes é primordial visto que as atividades realizadas no centro de Ciências são em pequenos grupos, seguindo uma lógica de visitação pelo espaço, com tempo pré-estabelecido e com objetivos definidos. Assim, os monitores devem organizar os grupos, guiá-los pelos espaços temáticos, controlar o tempo das atividades, fazer a troca dos grupos, direcionar alunos que queiram ir ao banheiro ou beber água, além de mantê-los focados, envolvidos e integrados nas atividades.

\footnotetext{
"Tenho como obrigação, sendo monitora, recepcionar bem os visitantes que chegam, para motivá-los a voltar outras vezes." (Monitor I)

"Sinto-me na obrigação de recepcionar bem estes visitantes para que, assim, eles se sintam acolhidos." (Monitor L)
}

\section{Categoria 5 - Zelar pelo espaço físico e integridade física e moral dos visitantes.}

Os monitores ressaltaram também o zelo que devem ter com os equipamentos e modelos expostos e com os visitantes. Demonstraram, em suas respostas, preocupação com os equipamentos que, se não manipulados da forma correta, podem vir a machucar alguém e o risco de algum equipamento ser quebrado e até mesmo furtado pelos visitantes. Também apontaram a necessidade de estarem sempre atentos à forma com que os alunos interagem com as atividades, como quando um monitor faz uma pergunta e algum aluno responde de maneira não apropriada, é preciso tomar cuidados para que o aluno não fique constrangido e que os demais integrantes do grupo não façam brincadeiras que venham a acanhar o sujeito. $\mathrm{O}$ monitor deve ter sensibilidade para perceber possíveis dúvidas, ou comentários dos visitantes e trabalhá-los de modo que o aluno se sinta à vontade, sem constrangimento, zelando também pela integridade moral dos indivíduos. 
"O monitor zela a segurança do aluno, pois alguns experimentos são perigosos, zela pelo cuidado dos alunos não quebrarem nada na sala ou até mesmo não furtarem nada, pois experimentos são caros." (Monitor K)

\section{Categoria 6 - Complementar o ensino escolar dos visitantes.}

Outro papel bastante recorrente nas respostas dos mediadores foi a complementação da educação formal dos visitantes recebida na escola. Muitos monitores escolhem as atividades que realizarão nos espaços temáticos de acordo com o nível de escolaridade dos estudantes e também de acordo com aquilo que estão estudando na escola na época da visitação. Os monitores pautam suas ações na ideia de, que na escola, os alunos têm contato com a teoria e, no Centro de Ciências, com a prática, um discurso também bastante comum entre os professores que agendam as visitas escolares monitoradas. Assim, o papel dos monitores, nessa dimensão educativa, está associado a algumas concepções pedagógicas, concepções de ensino e de aprendizagem e esse papel, ao ser praticado, deve estar em sintonia com a tendência pedagógica que rege as atividades da instituição.

“[...] transmitir um conteúdo através daquilo que eles estão vendo ou complementar aquilo que eles estão aprendendo na escola de uma maneira diferente, de um jeito mais descontraído e informal, fazendo com que eles participem mais e se sintam a vontade para qualquer tipo de pergunta." (Monitor L)

"Analiso minha função no Centro de Ciências como complementadora de parte do conhecimento formal dos alunos que aqui passam..." (Monitor I)

\section{Categoria 7 - Difundir conhecimento científico.}

Mostrar fenômenos e discutir sobre conceitos científicos, propor questionamentos sobre os fenômenos ou materiais observados pelos visitantes, difundir hipóteses e teorias da Ciência, relacionar as atividades com o cotidiano dos visitantes, contextualizar os conceitos científicos com o objetivo de aumentar o interesse, curiosidade e gosto dos visitantes pela Ciência são papéis que os monitores destacaram e que se enquadram nessa categoria.

No desempenho desses papéis, os monitores contribuem para o enriquecimento cultural do público visitante, considerando a Ciência como processo cultural. Na difusão de conhecimentos científicos, os monitores dos centros de Ciências no contexto da cultura científica têm a oportunidade de trabalhar junto ao público aspectos como a cultura gerada pela Ciência, a própria cultura da Ciência, a cultura por meio da ciência, cultura a favor da ciência, cultura voltada para a produção da ciência e a cultura voltada para a socialização da Ciência'. Nesse sentido, o papel do monitor se configura em estabelecer relações entre Ciência e Cultura.

\footnotetext{
"Para mim, o papel de um monitor é mostrar fenômenos e discutir sobre conceitos científicos que estão presentes no dia-a-dia das pessoas mas que estas não param para observar e até mesmo indagar porque determinado fenômeno ocorre ou não. Assim, meu papel é de contextualizar a Ciência e despertar no aluno o interesse ou curiosidade sobre ela." (Monitor J)
} 
A partir da análise das respostas foi possível perceber a leitura dos monitores sobre as ações que desempenham em seu fazer profissional, destacando uma série de atividades a serem cumpridas de maneira muito bem articulada e praticamente ao mesmo tempo. Johnson (2007, p. 33), em um de seus textos, propõe uma questão - $\mathrm{O}$ que podemos esperar de um mediador em um centro de Ciências? - e elenca na sequência, uma variedade de obrigações, algumas atuações que os mediadores podem desenvolver, às vezes, em um mesmo dia: (a) Atendente de estacionamento - orientando o trânsito, protegendo vagas para motoristas que são deficientes físicos; (b) Recepcionista - dando as boas-vindas, explicando o que está sendo exposto; (c) Locutor - utilizando o sistema de comunicação com o público; (d) Caixa - recebendo pagamentos, movimentando dinheiro; (e) Atendente de vestiário - guardando casacos, carrinhos de bebê, roupas; (f) Guia de visitas - mostrando aos visitantes como explorar o centro; (g) Especialista sobre o lugar - orientando a respeito de outras atrações locais, transporte, etc; (h) Mediador científico - explicando a Ciência que está por detrás das exposições; (i) Arrecadador de fundos e artista - variando o ritmo e o estilo de aprendizado; (j) Faxineiro - limpando as exibições, tirando o lixo, os restos de comida ... ou pior!; (k) Segurança - evitando problemas: mau comportamento, intrusos, proteção infantil; (l) Vendedor - vendendo ações, ingressos para eventos futuros, lembranças, bebidas; (m) Apresentador - apresentando shows e demonstrações e (n) Fonte de informações para visitantes - avaliando as peças em exibição e os programas.

O monitor de centro de Ciências, ao atuar em uma visita mediada, deve fazer uso de uma série extensa de elementos que são constitutivos de sua prática profissional e que são adquiridos e aprimorados a partir das experiências vivenciadas. A prática profissional desse sujeito deve levar em conta os aspectos da pedagogia museal, como o lugar, o tempo, os objetos e a linguagem (Marandino, 2008). Esse autor, ao tratar da temática da mediação, discutindo o papel do mediador nos museus, aponta que esse deve estar atento ao tempo gasto frente a um aparato, painel ou objeto da exposição e ao espaço percorrido pelos visitantes para evitar o cansaço. Esse profissional também deve obter informações sobre o perfil dos visitantes, nível de escolaridade, conhecer as concepções prévias que esses visitantes trazem de suas vivências, procurando estabelecer ligações entre tais conhecimentos e entre aqueles que são apresentados nas exposições. Também devem "elaborar estratégias eficazes e estimulantes, que articulem processos educativos e comunicativos adequados e os objetivos esperados nas ações que participam", considerando que é "um momento de criação e de produção de conhecimento próprio dos mediadores" (MARANDINO, 2008, p. 20). 


\section{CONSIDERAÇÕES FINAIS}

A partir do levantamento na literatura sobre quem são, o que fazem e sobre a importância dos mediadores de centros e museus de Ciências, foi possível encontrar uma série de informações, de concepções que, em alguns casos, convergem em pontos comuns. Foi possível perceber também que os mediadores apresentam posturas e comportamentos diferentes quando atuam em uma visita escolar em relação à visita não-escolar. A literatura aponta que os mediadores têm a função de auxiliar nos experimentos, de dar informações e esclarecer dúvidas sobre as exposições, de mediar processos de construção do conhecimento, de concretizar a comunicação entre a instituição e o público de focalizar a atenção do visitante, de provocar discussões, de incitar a observação, de orientar grupos; e animar o ambiente, de fazer a pergunta certa para aprofundar e enriquecer a experiência do visitante, dentre outras tantas. Diante de tantas possibilidades de ação e papéis atribuídos a estes profissionais, cabe pensar a questão da formação e atuação profissional destes mediadores visto que eles são essenciais para as instituições de educação não-formal que prezam a mediação humana (SILVA, 2009).

Os dados construídos e analisados a partir da contribuição dos mediadores como sujeitos da pesquisa apontaram que, durante as visitas escolares, os papéis que cabem aos mediadores são: (a) mediar o conhecimento; (b) explicar os conceitos científicos envolvidos nas exposições; (c) apresentar os espaços temáticos; (d) receber e organizar os visitantes; (e) zelar pelo espaço físico e integridade física e moral dos visitantes; (f) complementar e ensino escolar dos visitantes e (g) difundir conhecimento científico. Talvez algumas dessas categorias de ações não aparecessem se a pergunte fosse direcionada para a visita com o público não-escolar. A visita escolar mediada tem suas especificidades e se constitui em uma categoria de análise interessante para que possamos compreender melhor como ocorre o processo de educação e comunicação a partir dessa dimensão.

Com esse trabalho pudemos obter informações sobre alguns dos papéis que são desempenhados pelos mediadores de centro de Ciências. Esses dados podem auxiliar na fundamentação dos processos de formação profissional de monitores nas instituições como centros e museus de Ciências. É importante que o monitor e a equipe do serviço educativo dos museus conheçam esses papéis e trabalhem no sentido de explorar as especificidades de cada um deles. Os resultados podem contribuir para o campo da Educação em centros e museus de Ciências, visto que o mediador é um dos personagens centrais nessas instituições e que, portanto, conhecer o que literatura aponta a respeito desses sujeitos e conhecer o que alguns desses sujeitos dizem sobre seus papéis é algo fundamental para orientar ações que ocorrem no contexto da educação não-formal. 


\section{NOTAS}

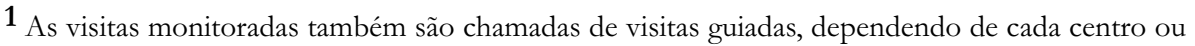
museu de Ciências. Poderíamos também adotar o termo visita mediada, partindo da perspectiva da mediação humana, como forma de comunicação entre público e exposição, tendo o mediador como figura central nesse processo.

2 Publicação original em língua francesa: (2003) La médiation: la communication en procès?, Médiations \& Médiateurs, 19. Tradução: Maria Rosário Saraiva; revisão: Maria Rosário Saraiva e Helena Santos.

3 Ribeiro (2005) usa como exemplo, o caso do Visionárium de Santa Maria da Feira e do Pavilhão do Conhecimento, em Lisboa/Portugal.

4 Gaspar (2006) fez uso principalmente da obra "Pensamento e linguagem". São Paulo: Editora Martins Fontes, 1987.

5 Centro de Divulgação Científica da Universidade de São Paulo, localizado na cidade São Paulo.

6 Com base na teoria sociointeracionista de Vigotski.

7 Zona de Desenvolvimento Imediato.

8 Todos os monitores, antes de iniciarem as atividades como mediadores passam por um curso de formação inicial, oferecido pela própria Instituição. Tal curso aborda os saberes da mediação, as questões inerentes à educação não-formal e divulgação científica, comunicação para os diferentes tipos de público, conceitos científicos explorados a partir dos experimentos e aparatos, dentre outros temas.

9 A expressão cultura científica oferece várias possibilidades de sentido, destacando por exemplo, três possibilidades como cultura da Ciência, cultura pela Ciência e cultura para a Ciência, segundo Carlos Vogt declara na reportagem "A espiral da cultura científica", disponível em http://www.comciencia.br/reportagens/cultura/cultura01.shtml. Essas três possibilidades se ampliam nas distinções citadas aqui nesse texto.

\section{REFERÊNCIAS BIBLIOGRÁFICAS}

ANDRÉ, M. E. D. A. Estudo de caso em pesquisa e avaliação educacional. Brasília: Líber Livro Editora, 2005.

AZEVEDO, M. R. P. M. Dinâmicas de aprendizagem nos museus: a mediação. Revista en-red (online), p. 1-20. Disponível em:

<http://www.rede-educacao-artistica.org/docs/m_red/MariadoRosarioAzevedo_DINAMICASDEAPRENDIZAGEMNOSMUSEUS.pdf $>$. Acesso em: 20 de outubro de 2009.

BARDIN, L. Análise de conteúdo. Lisboa: Edições 70, 1977; 2000.

BONATTO, M. P. O.; SEIBEL, M. I; MENDES, I. A. Ação mediada em museus de Ciências: o caso do Museu da Vida. In: MASSARANI, L. (Org). Diálogos \& Ciência: mediação em museus e centros de Ciência. Rio de Janeiro: Casa de Oswaldo Cruz/Fiocruz, 2007, p. 48-55.

DAVALLON, J. A mediação: a comunicação em processo? Disponível em:

$<$ http://prisma.cetac.up.pt/A_mediacao_a_comunicacao_em_processo.pdf $>$. Acesso em: 20 de outubro de 2009.

FAHL, D. D. Marcas do ensino escolar de Ciências presentes em Museus e Centros de Ciências: um estudo da Estação Ciência - São Paulo e do Museu Dinâmico de Ciências de Campinas - MDCC. 2003. Dissertação (Mestrado em Educação) - Faculdade de Educação, Universidade Estadual de Campinas, 2003.

GASPAR, A. Museus e centros de Ciências - conceituação e proposta de um referencial teórico. 1993. Tese (Doutorado em Didática) - Universidade de São Paulo, 1993.

GIL, A. C. Métodos e técnicas de pesquisa social. São Paulo: Editora Atlas, 3 ed., 1991, p. 124-133.

GOUVEIA, M. T. J. et al. A mediação de visitas no Jardim Botânico do Rio de Janeiro. In: 
MASSARANI, L. (Org). Diálogos \& Ciência: mediação em museus e centros de Ciência. Rio de Janeiro: Casa de Oswaldo Cruz/Fiocruz, 2007, p. 82-88.

GRUSMAN, C; SIQUEIRA, V. H. F. O papel educacional do museu de Ciências: desafios e transformações conceituais. Revista Electrónica de Enseñanza de las Ciencias, v. 6, n. 2, 402-423, 2007.

JOHNSON, C. Capacitação de mediadores em centros de Ciências: reflexões sobre o Techniquest. In: MASSARANI, L. (Org). Diálogos \& Ciência: mediação em museus e centros de Ciência. Rio de Janeiro: Casa de Oswaldo Cruz/Fiocruz, 2007. p. 32-38.

MARANDINO, M. (Org.) Educação em Museus: a mediação em foco. São Paulo, SP: Geenf/FEUSP, 2008.

MASSARANI, L. (Org). Diálogos \& Ciência: mediação em museus e centros de Ciência. Rio de Janeiro: Casa de Oswaldo Cruz/Fiocruz, 2007. 92p.

MATSUURA, O. T. Teatro cósmico: mediação em planetários. In: MASSARANI, L. (Org). Diálogos \& Ciência: mediação em museus e centros de Ciência. Rio de Janeiro: Casa de Oswaldo Cruz/Fiocruz, 2007. p. 76-80.

MORAES, R. et al. Mediação em museus e centros de Ciências: o caso do Museu de Ciências e Tecnologia da PUC-RS. In: MASSARANI, L. (Org). Diálogos \& Ciência: mediação em museus e centros de Ciência. Rio de Janeiro: Casa de Oswaldo Cruz/Fiocruz, 2007. p. 56-67.

PAVÃO, A. C.; LEITÃO, A. Hands-on? Minds-on? Hearts-on? Social-on? Explainers-on? In: MASSARANI, L. (Org). Diálogos \& Ciência: mediação em museus e centros de Ciência. Rio de Janeiro: Casa de Oswaldo Cruz/Fiocruz, 2007. p. 40-47.

RIBEIRO, M. E. C. Os museus e centros de Ciência como ambientes de aprendizagem. 2005. Dissertação (Mestrado em Educação) - Instituto de Educação e Psicologia, Universidade do Minho, Braga, PT, 2005.

RIBEIRO, M. G; FRUCCHI, G. Mediação - a linguagem humana dos museus. In: MASSARANI, L. (Org). Diálogos \& Ciência: mediação em museus e centros de Ciência. Rio de Janeiro: Casa de Oswaldo Cruz/Fiocruz, 2007. p. 68-74.

RODARI, P.; MERZAGORA, M. Mediadores em museus e centros de Ciências: status, papéis e capacitação. Uma visão europeia. In: MASSARANI, L. (Org). Diálogos \& Ciência: mediação em museus e centros de Ciência. Rio de Janeiro: Casa de Oswaldo Cruz/Fiocruz, 2007. p. 8-21.

SÁPIRAS, A. Aprendizagem em museus: uma análise das visitas escolares no Museu Biológico do Instituto Butantan. 2007. Dissertação (Mestrado em Educação) - Faculdade de Educação, Universidade de São Paulo, 2007.

SILVA, C. S. Formaşão e atuaşão de monitores de visitas escolares de um centro de Ciências: saberes e prática reflexiva. 2009. 141f. Dissertação (Mestrado em Educação para a Ciência) - Faculdade de Ciências, Universidade Estadual Paulista, Bauru, 2009.

SILVA, C. S; GASPAR, A. Investigando as interações sociais que ocorrem entre monitores e visitantes de um centro de Ciências durante as atividades de Química. In: ENCONTRO NACIONAL DE PESQUISA EM EDUCAÇÃO EM CIÊNCIAS, 6., 2007, Florianópolis. Anais..., Belo Horizonte: ABRAPEC, 2007.

STANDERSKI, L. Monitorias em Museus de Ciências: uma perspectiva reflexiva. Relatório Final de Iniciação Científica. São Paulo: Faculdade de Educação/Universidade de São Paulo, 2007.

STUCHI, A. M. ; FERREIRA, N. C. Análise de uma exposição científica e proposta de intervenção. Revista Brasileira de Ensino de Física, v. 25, n. 2, 207-217, junho, 2003.

Data de recebimento: $24 / 11 / 2009$

Data de aprovação: $18 / 10 / 2010$

Data da versão final: $21 / 01 / 2011$ 